\title{
Explaining the physiological cationic distribution in erythrocytes: The murburn perspective
}

\author{
Kelath Murali Manoj* \\ *Corresponding author: (murman@satyamjayatu.com) \\ Satyamjayatu: The Science \& Ethics Foundation \\ Snehatheeram, Kulappully, Shoranur-2 (PO), Kerala, India-679122.
}

\begin{abstract}
Living cells are characterized by the interesting disparity in the distribution of monovalent and divalent cations, as per the order: $\mathrm{K}^{+}>\mathrm{Na}^{+}>\mathrm{Mg}^{2+}>>\mathrm{Ca}^{2+}$. Classical biologists attribute this to energy-expended and affinity-driven processes mediated by membrane-embedded proteins. Independent physicists had proposed ionic adsorption at various interfaces and/or differences in hydration shell characteristics of the ions as the reasons for the same Herein, human erythrocytes are considered as a simple 'living cell' model. Energy metabolism-based outcomes (murburn equilibriums) and the dissolved-phase proteins' innate ability to bind/adsorb ions selectively are suggested as the integral rationale for the observed phenomenon.
\end{abstract}

Keywords: homeostasis, murburn concept, membrane ion-pumps, adsorption, ion-distribution in cells, Hofmeister series/effect 


\section{Introduction}

Living beings possess unique abilities to concentrate ions within, and this facet is necessary for discharging the essential/vital functions. This ability is a long-standing conundrum in biology. Herein, the distribution ratios of the four cations- $\mathrm{Na}^{+}, \mathrm{K}^{+}, \mathrm{Mg}^{2+}$ and $\mathrm{Ca}^{2+}$ within human red blood corpuscles (RBC or erythrocytes) are addressed, from an ab initio perspective.

\section{Methodology}

The consensus distribution of major cations in human erythrocytes and serum, earlier compiled from various reliable sources was perused. Solubility of various salts in water at $20{ }^{\circ} \mathrm{C}$ were availed from CRC Handbook of Chemistry and Physics (and Wikipedia) and analyzed with simple mathematical operations to see if there existed any simple and tangible correlations existed between them. Further, old and recent schools of thoughts in cellular physiology were also considered to explain/rationalize the findings.

\section{Results and Discussion}

Since erythrocytes lack nucleus, they were chosen as simple cellular model, to minimize complications arising from genetic-level regulations.

Absolute and relative concentrations of various ions in erythrocytes: The compiled data (Manoj and Tamagawa, 2020) and attempts to draw forthright correlations between them are given in Table 1. The distribution ratio of the four cations $\left(\mathrm{K}^{+}, \mathrm{Na}^{+}, \mathrm{Ca}^{2+} \& \mathrm{Mg}^{2+}\right)$ inside the $\mathrm{RBC}$ was found to be $73: 6.3: 0.003: 1$, respectively. When compared with respect to a single ion of calcium, $\sim 2.4 \times 10^{4} \mathrm{~K}^{+}$and $2.1 \times 10^{3} \mathrm{Na}^{+}$ions are found in erythrocytes! A simple analysis of the compiled data did not give any tangible correlation of the monovalent or divalent ions, with respect to their concentrations inside or outside. This finding does not align well with the operation of biologically deterministic membrane-pumps, which are supposed to work with specific ratios (Voet \& Voet, 2011). Further, since RBC lack mitochondria, they cannot avail 
ample energy resources for maintaining this highly cost-ineffective exercise. For more arguments in this regard, please refer my earlier communication (Manoj \& Tamagawa, 2020).

Table 1: Distribution profiles of the major cations and anions in human erythrocytes

\begin{tabular}{ccccccccc}
\hline Item & $\begin{array}{c}\mathbf{K}(+) \\
\text { (a) }\end{array}$ & $\begin{array}{c}\mathbf{N a}(+) \\
(\mathbf{b})\end{array}$ & $\begin{array}{c}\mathbf{C a}(++) \\
(\mathbf{a})\end{array}$ & $\begin{array}{c}\mathbf{M g}(++) \\
\text { (b) }\end{array}$ & $\begin{array}{c}\mathbf{C l}(-) \\
\text { (a) }\end{array}$ & $\begin{array}{c}\mathbf{H C O}_{3}(-) \\
\text { (b) }\end{array}$ & Protein (?) & Acetate (-) \\
\hline RBC (in) & $139 \mathrm{mM}$ & $12 \mathrm{mM}$ & $5.7 \mu \mathrm{M}$ & $1.9 \mathrm{mM}$ & $4 \mathrm{mM}$ & $\sim 12 \mathrm{mM}$ & $\sim 138 \mathrm{mM}$ & $\mathrm{NA}$ \\
Serum (out) & $4 \mathrm{mM}$ & $145 \mathrm{mM}$ & $1.8 \mathrm{mM}$ & $0.8 \mathrm{mM}$ & $116 \mathrm{mM}$ & $\sim 29 \mathrm{mM}$ & $\sim 9 \mathrm{mM}$ & $0.25 \mathrm{mM}$ \\
In/Out & 35 & 0.08 & 0.003 & 2.4 & 0.034 & 0.414 & 15.3 & NA \\
In (a/b) & 12 & $\mathrm{NA}$ & 0.003 & $\mathrm{NA}$ & 0.333 & $\mathrm{NA}$ & $\mathrm{NA}$ & $\mathrm{NA}$ \\
Out (b/a) & $\mathrm{NA}$ & 36 & $\mathrm{NA}$ & 0.44 & $\mathrm{NA}$ & 0.25 & $\mathrm{NA}$ & $\mathrm{NA}$ \\
\hline
\end{tabular}

(NA: not applicable or not available)

Does a simple physical rationale exist for the distributional anomaly of cations? A compilation of the abundance of the ions on earth, weight, solubility of the respective chloride (an abundant anion in nature and in physiological realms) dimensions, dimensions, and some thermodynamic properties (Bazhin, 2020) is presented in Table 2. It can be envisaged that the relative abundance/solubility of the ions could determine their bioavailability. Further, ionic mass and charge would determine work done in moving ions across membranes. None of the first three parameters were found to directly/tangibly correlate to the physiological distribution of the cations, when considering the full spectrum (of $\mathrm{K}-\mathrm{Na}-\mathrm{Ca}-\mathrm{Mg}$ ). Ionic dimensions would determine filtration/pumping (through membrane proteins) and also affect the hydration shell sizes. Therefore, it is a very important criterion for both the classical membrane theorists (Voet \& Voet, 2011) and the alternative schools of thought (like association-induction hypothesis, as seen in Gilbert Ling's works at www.gilbertling.org). This is the reason why data are presented in the order of decreasing ionic radius in Tables $1 \& 2$. Yet again, it is difficult for this author to envisage that membrane pores could kinetically/viably enable a selective differentiation of di- or mono- valent ions of dimensions ranging $\sim 1.7 \AA\left(\mathrm{Mg}^{2+}\right)$ to $\sim 2.3 \AA\left(\mathrm{Ca}^{2+}\right.$ or $\left.\mathrm{Na}^{+}\right)$to $\sim 3.0 \AA\left(\mathrm{K}^{+}\right)$. That is: while the smaller species can be easily selected, the larger species would invariably/statistically bring along the smaller one, if size/charge were the deterministic criteria. This predicament would necessitate directional pumps/channels for each of the species, and such processes would not be efficient. Table 2 shows that ionic radius is inversely correlated to Gibbs free energy of formation or $\Delta_{\mathrm{f}} G^{{ }^{\circ}}{ }_{\text {aq }}$ (i.e. as ionic radius decreases, $\Delta_{\mathrm{f}} G^{\prime{ }^{\prime}}$ aq increases) and directly correlated to Gibbs solvation energy or G.S.E. (i.e. as ionic radius decreases, G.S.E. also 
decreases). While the differences in thermodynamic properties are significant, they are unidirectional with respect to ionic size. Therefore, it cannot justify the observed physiological outcome in Table 1, which shows that the larger monovalent ion $\left(\mathrm{K}^{+}\right)$and the smaller divalent ion $\left(\mathrm{Mg}^{2+}\right)$ are preponderant in cells. In this regard, Ling's assertion that the binding of the 'cardinal ligand' of ATP to proteins alters the latter's conformations and rearranges the waterlattice around them is not amply supported by spectroscopic or experimental data. Therefore, “ion-water re-organization mediated by proteins+ATP" does not appear to be the direct factor in determining the outcomes. Clearly, none of the parameters in Table 2 provide a direct or simple/tangible rationale for the physiological distribution of cations.

Table 2: Fundamental physical attributes of the four cations explored herein

\begin{tabular}{|c|c|c|c|c|c|c|}
\hline S. No. & Criteria & $K(+)$ & $\mathrm{Na}(+)$ & $\mathrm{Ca}(++)$ & $M g(++)$ & Average \pm st.dev. \\
\hline 1 & Abundance & $2.09 \%$ & $2.36 \%$ & $4.15 \%$ & $2.33 \%$ & $2.73 \pm 1 \%$ \\
\hline 2 & Solubility (CI) & $4.6 \mathrm{M}$ & $6.15 \mathrm{M}$ & $6.71 \mathrm{M}$ & $5.74 \mathrm{M}$ & $5.8 \pm 0.9 \mathrm{M}$ \\
\hline 3 & Atomic mass & $39 \mathrm{~g}$ & $23 \mathrm{~g}$ & $40 \mathrm{~g}$ & $24.3 \mathrm{~g}$ & $31.6 \pm 9 \mathrm{~g}$ \\
\hline 4 & Ionic radius & $152 \mathrm{pm}$ & $116 \mathrm{pm}$ & 114 pm & $86 \mathrm{pm}$ & $117 \pm 27 \mathrm{pm}$ \\
\hline 5 & $\Delta_{\mathrm{f}} G^{\prime \mathrm{o}} \mathrm{aq}$ & $129 \mathrm{~kJ} / \mathrm{mol}$ & 151 kJ/mol & $271 \mathrm{~kJ} / \mathrm{mol}$ & $370 \mathrm{~kJ} / \mathrm{mol}$ & $230 \pm 112 \mathrm{~kJ} / \mathrm{mol}$ \\
\hline 6 & G.S.E. & $-352 \mathrm{~kJ} / \mathrm{mol}$ & $-424 \mathrm{~kJ} / \mathrm{mol}$ & $-1608 \mathrm{~kJ} / \mathrm{mol}$ & $-1931 \mathrm{~kJ} / \mathrm{mol}$ & $-1079 \pm 809 \mathrm{~kJ} / \mathrm{mol}$ \\
\hline
\end{tabular}

Predictive exploration based on murburn concept: Cells can be deemed to work as redox machines, and cellular redox processes are based on electron transfers and equilibriums between its component molecules and ions. Murburn concept is an interactive equilibrium of molecules, ions and spontaneously formed radicals in cell metabolism/physiology (Manoj, 2018; Manoj, 2020). Till date, it has presented explanations for diverse fundamental aspects of life: moiety and electron transfers mediated by heme-/flavin- enzymes (Manoj, 2006; Manoj \& Hager, 2008; Manoj et al., 2010; Andrew et al., 2012; Parashar et al., 2014; Manoj et al., 2016a-b), aerobic respiration (Manoj et al., 2019a-b, Manoj et al., 2020), oxygenic photosynthesis (Manoj \& Manekkathodi, 2021), xenobiotic metabolism (Manoj et al., 2016c, Parashar \& Manoj, 2021), idiosyncratic/hermetic dose responses (Parashar et al., 2018), homeostasis/trans-membrane potential (Manoj \& Tamagawa, 2020), thermogenesis (Manoj et al., 2018), signal transduction in vision (Manoj \& Jacob, 2020), etc. Since cellular bioenergetic routines are fundamentally based in murburn principles, it is forthright to postulate that cellular composition would be dictated by 
the catalysts/intermediates/products of metabolism. With relevance to context, those ions that are preferred by the constituent proteins (which are the stable and relatively non-changing components in cells) and intermediates/products of respiration (those species that are in high turnovers within the cell) would have the propensity to dictate the outcomes. Based upon such an intuitive thought-line, the solubility profiles of four anions of respiratory relevance (for which we could access data from literature: carbonate, acetate, bicarbonate and phosphate) were probed. Table 3 presents the summary of this data, which shows that two anions gave a solubility profile of the same relative order as found in RBC for all the four cations, and two more anions gave good correlations with at least three of the cations. Unlike the solubility data for chloride, these anions show a high degree of selectivity/variance for the four cations. Clearly, the solubility of these salts must contribute to achieving the physiological outcomes. Carbonate/bicarbonate and acetate are directly the output of carbon metabolism (aerobic respiration) and phosphate is also involved in bioenergetic turnovers. Particularly, it can be seen that phosphate is very selective to potassium, as opposed to calcium; thereby explaining the oddity discussed for Table 1. So, the highly skewed cationic distribution primarily results as a direct outcome of the powering murburn equilibriums/fluxes (Manoj, 2018; Manoj, 2020) transpiring in metabolism/physiology. Contrary to earlier perceptions, one-electron processes could be facile in cells and this would be a more plausible explanation for several phenomena than a merely adsorption-based explanation. For solvation, the solvent-lattice must be broken first to introduce a cavity, into which ions can be placed; this is both enthalpically and entropically not a favored step. In this regard, within the physiologically ordered milieu, the solvation of 'anion+cation' couplet appears to be aided by discretized murburn equilibriums.

Table 3: Absolute and relative solubility ratios of some salts in water

\begin{tabular}{cccccc}
\hline S. No. & Anion & $\mathbf{K ~ ( + )}$ & $\mathbf{N a ~ ( + )}$ & $\mathbf{C a ~ ( + + ) ~}$ & $\mathbf{M g}(++)$ \\
\hline 1 & Carbonate & $8.04 \mathrm{M}$ & $2.02 \mathrm{M}$ & $70 \mu \mathrm{M}$ & $4.6 \mathrm{mM}$ \\
& (Ratio) & $\mathbf{1 . 7 \times 1 0 ^ { 3 }}$ & $\mathbf{4 . 4 \times 1 0 ^ { 2 }}$ & $\mathbf{1 . 5} \times \mathbf{1 0}^{-1}$ & $\mathbf{1}$ \\
2 & Acetate & $26 \mathrm{M}$ & $5.7 \mathrm{M}$ & $2.2 \mathrm{M}$ & $3.75 \mathrm{M}$ \\
& (Ratio) & $\mathbf{6 . 9}$ & $\mathbf{1 . 5}$ & $\mathbf{0 . 6}$ & $\mathbf{1}$ \\
3 & Bicarbonate & $2.24 \mathrm{M}$ & $1.14 \mathrm{M}$ & $1.02 \mathrm{M}$ & $4.2 \mathrm{mM}$ \\
& (Ratio) & $\mathbf{5 . 3 \times 1 0 ^ { 2 }}$ & $\mathbf{2 . 7 \times 1 0 ^ { 2 }}$ & $2.4 \times 10^{2}$ & $\mathbf{1}$ \\
4 & Phosphate & $4.35 \mathrm{M}$ & $0.74 \mathrm{M}$ & $64.5 \mu \mathrm{M}$ & $1 \mu \mathrm{M}$ \\
& (Ratio) & $\mathbf{6 . 7 \times 1 0 ^ { 4 }}$ & $\mathbf{1 . 1 \times 1 0 ^ { 4 }}$ & $\mathbf{1}$ & $1.6 \times 10^{-2}$ \\
\hline
\end{tabular}


The total concentration of major cations $\left(\mathrm{K}^{+}\right.$and $\left.\mathrm{Na}^{+}\right)$turns out to be $\sim 150 \mathrm{mM}$ (both in and out of RBC) and the minor cations $\left(\mathrm{Ca}^{2+}\right.$ and $\left.\mathrm{Mg}^{2+}\right)$ add up to $2 \%$ of the above value (Table 1). The law of electro-neutrality of phases dictates a similar concentration range of the total anionic charges in each phase. From an ab initio perspective, the major difference between erythroplasm and serum is the concentration of proteins. We also know that proteins are the major source of negative charges in the cell (Table 1). It is long known that Hofmeister series (Okur et al., 2017) indicates that the experimentally observed cation binding/adsorption of most cytoplasmic proteins is approximated in the order $\mathrm{K}^{+}>\mathrm{Na}^{+}>\mathrm{Mg}^{++}>\mathrm{Ca}^{++}$. Therefore, both binding affinities of bulk-phase proteins and ions involved in metabolic turnovers can come together (as an integral function) to achieve the physiological distribution of ions in cells. This is a simple and parsimonious deduction, and it is also supported by the consideration that highly sophisticated membrane-embedded ion-pumps would not be needed for the evolution of life in the primordial stages. Further, attainment of the physiological distribution of ions would not require any intelligent control via membrane-proteins' concentrations/functions or through exorbitant expenditure of ATP. In short, a good analogy comes to mind, to effectively capture the essence of the overall process. The number or type of people that reside in a locale (say, a county or country) is decided by screening at the borders (membrane theory components) and by the discretion of citizens (adsorption theory components). The elements that murburn theory enlists include the dynamics and mechanistic of the overall process- why some borders can't be policed, why some residents do not like drifters, etc. The findings herein do not negate the existence of membrane-embedded ion-channels but call for a revisit of the mechanisms for cellular homeostasis and trans-membrane potential (TMP) (Manoj \& Tamagawa, 2020).

\section{Declarations}

Satyamjayatu: The Science \& Ethics Foundation sponsored this work. The author has no conflicts of interests to declare.

\section{References}

Andrew, D. et al. The intriguing enhancement of chloroperoxidase mediated one-electron oxidations by azide, a known active-site ligand. Biochem. Biophys. Res. Commun. 415 (2012) 646-649.

Bazhin, N. M. Standard values of the thermodynamic functions of the formation of ions in an aqueous solution and their change during salvation. J. Phys. Chem. A.124 (2020) 11051-11060. 
Hofmeister, F. Zur Lehre von der Wirkung der Salze. Arch. Exp. Pathol. Pharmacol. 24 (1888) 247-260.

Manoj, K. M. Chlorinations catalyzed by chloroperoxidase occur via diffusible intermediate(s) and the reaction components play multiple roles in the overall process. Biochim. Biophys. Acta 1764 (2006) 13251339.

Manoj, K. M. \& Hager, L. P. Chloroperoxidase, a Janus enzyme. Biochemistry 47 (2008) 2997-3003.

Manoj, K. M. et al. Cytochrome P450 reductase: a harbinger of diffusible reduced oxygen species. PLoS One 5 (2010) e13272.

Manoj, K. M. et al. Electron transfer amongst flavo- and hemo-proteins: diffusible species effect the relay processes, not protein-protein binding. RSC Adv. 6 (2016a) 24121-24129.

Manoj, K. M. et al. Atypical profiles and modulations of heme-enzymes catalyzed outcomes by low amounts of diverse additives suggest diffusible radicals' obligatory involvement in such redox reactions. Biochimie 125 (2016b) 91-111.

Manoj, K. M. et al. Functioning of microsomal cytochrome P450s: murburn concept explains the metabolism of xenobiotics in hepatocytes. Front. Pharmacol. 7 (2016c) 161.

Manoj, K. M. The ubiquitous biochemical logic of murburn concept. Biomed. Rev. 29 (2018) 89-98.

Manoj, K. M. et al. Murburn scheme for mitochondrial thermogenesis. Biomed. Rev. 29 (2018) 73-82.

Manoj, K. M. et al. Aerobic respiration: proof of concept for the murburn perspective. J. Biomol. Struct. Dyn. 37 (2019a) 4524-4556.

Manoj, K. M. et al. Chemiosmotic and murburn explanations for aerobic respiration: predictive capabilities, structure-function correlations and chemico-physical logic. Arch. Biochem. Biophys. 676 (2019b) 108128.

Manoj, K. M. Murburn concept: A paradigm shift in cellular metabolism and physiology. Biomol. Concepts 11 (2020) 7-22.

Manoj, K. M. et al. Acute toxicity of cyanide in aerobic respiration: Theoretical and experimental support for murburn explanation. Biomol. Concepts 11 (2020) 32-56.

Manoj, K. M. \& Tamagawa, H. A review of the mechanisms for cellular homeostasis and electrophysiological responses: Membrane theory, association-induction hypothesis and murburn concept. OSF Preprints (2020). doi: 10.31219/osf.io/e2ynk

Manoj, K. M. \& Jacob, V. D. The murburn precepts for photoreception. Biomed. Rev. 31 (2020). In press.

Manoj, K. M. \& Manekkathodi, A. Light's interaction with pigments in chloroplasts: The murburn perspective. J. Photochem. Photobiol. 5 (2021) 100015.

Okur, H. I. et al. Beyond the Hofmeister series: Ion-specific effects on proteins and their biological functions. J. Phys. Chem. B. 121 (2017) 1997-2014.

Parashar, A. et al. Cyanide does more to inhibit heme enzymes, than merely serving as an active-site ligand. Biochem. Biophys. Res. Commun. 455 (2014) 190-193.

Parashar, A. et al. Murburn Concept: a molecular explanation for hormetic and idiosyncratic dose responses. Dose Response 16 (2018) 1559325818774421.

Parashar, A. \& Manoj K. M. Murburn precepts for cytochrome P450 mediated drug/xenobiotic metabolism and homeostasis. Curr. Drug Metab. 1 (2021). doi: 10.2174/1389200222666210118102230.

Voet, D. \& Voet J. G. Biochemistry $4^{\text {th }}$ edition. (2011) Wiley, Hoboken, USA. 